\title{
Tres documentos iconográficos celtibéricos de la capital segoviana.
}

\author{
Juan Francisco BLANCO GARCÍA \\ Universidad Autónoma de Madrid
}

\begin{abstract}
Resumen
El vaciado en 1974 del solar en el que estuvo situado el antiguo Colegio de los Hermanos Maristas, en la ciudad de Segovia, trajo consigo la exhumación de abundantes restos arqueológicos de las épocas celtibérica y romana. Entre los materiales recuperados, sobre todo cerámicos, se encontraban algunos fragmentos interesantes para conocer algo más de quienes vivieron en este enclave en dichas épocas. En el presente trabajo nos centraremos en tres documentos del universo iconográfico celtibérico segoviano: una cabeza de caballo modelada en arcilla, la imagen parcialmente conservada de un jinete armado con lanza que fue pintada en un vaso cerámico y unos peces igualmente pintados en un recipiente.
\end{abstract}

Palabras clave: Cerámica celtibérica pintada, Jinete con lanza, Caballo de barro, Iconografía, Segunda Edad del Hierro, Ciudad arévaca de Segovia.

\section{Summary}

During the year 1974, when were demolished the building of the ancient Hermanos Maristas College, in the city of Segovia, many archaeological artifacts of the celtiberian and roman periods were recuperated. Pottery was, obviously, the most important finds. In this paper we study three celtiberian pieces: a horse's head clay figurine, a mounted cavalryman with a lance on the left hand that was painted on a pottery vessel, an a sequence of fishes painted in a pottery recipient too.

Keywords: Celtiberian painted pottery, Mounted warrior with spear, Clay horse figurine, Iconography, Second Iron Age, Arevacan city of Segovia.

Segovia es una de las ciudades celtibéricas a la que se le supone una destacada entidad porque, además de ser citada por varios autores clásicos y haber acuñado moneda de tipo celtibérico aunque en tiempos muy

1 Está demás entrar aquí en las discusiones que desde hace prácticamente cuatro siglos vienen produciéndose en torno a la correspondencia entre la Segovia mencionada por los autores clásicos, y a la vez emisora de los ases que portan la leyenda SEGOVIA, y la capital del Eresma. A pesar de que en la península Ibérica hay varios yacimientos de la Edad avanzados y con texto ya en latín', el solar en el que se encuentra emplazada reúne todas las condiciones para que así fuera. Se levantó sobre un extenso cerro amesetado que, con poca inversión de medios y trabajo

del Hierro que actualmente se conocen con este mismo nombre, creemos que pocas dudas razonables se pueden aducir para pensar que la Segovia del acueducto no fuera realmente la citada por aquéllos y la que acuñó tales numismas (Véase, a este respecto, Blanco García, 2001: 118-119, notas 11 y 12). 
para el acondicionamiento del terreno, permitía una cómoda instalación de las edificaciones; contaba con excelentes condiciones naturales para su defensa; a sus pies se extendían amplias vegas regadas por los ríos Clamores y Eresma; tanto estos ríos como los numerosos manantiales que hay en las faldas del propio cerro y sus inmediaciones, muchos de los cuales aún están en uso, garantizaban el abastecimiento regular de agua potable a la población (Blanco García, 2002: 177-178, fig. 1); estaba situada en un punto estratégico, cruce de caminos para las comunicaciones entre dos importantes regiones económicas cuales eran el centro del valle del Duero y el centro del Tajo, por un lado, y además a mitad del camino que, a lo largo del piedemonte septentrional del Sistema Central, unía el área vettona y la Celtiberia soriana, por otro ${ }^{2}$. A pesar de todo esto, se puede decir que es uno de los núcleos celtibéricos peor conocidos desde el punto de vista arqueológico debido, en primer lugar, a que la ciudad moderna está empastando férreamente a las que subyacen bajo ella y, en segundo lugar, a las seculares remodelaciones urbanísticas -con las consiguientes destrucciones de los restos anteriores- que en ella han tenido lugar a lo largo del tiempo. Primero, las de época romana, que debieron de ser importantes; después, las medievales, modernas y contemporáneas. Todas han supuesto la destrucción generalizada y sistemática de los restos de la ciu-

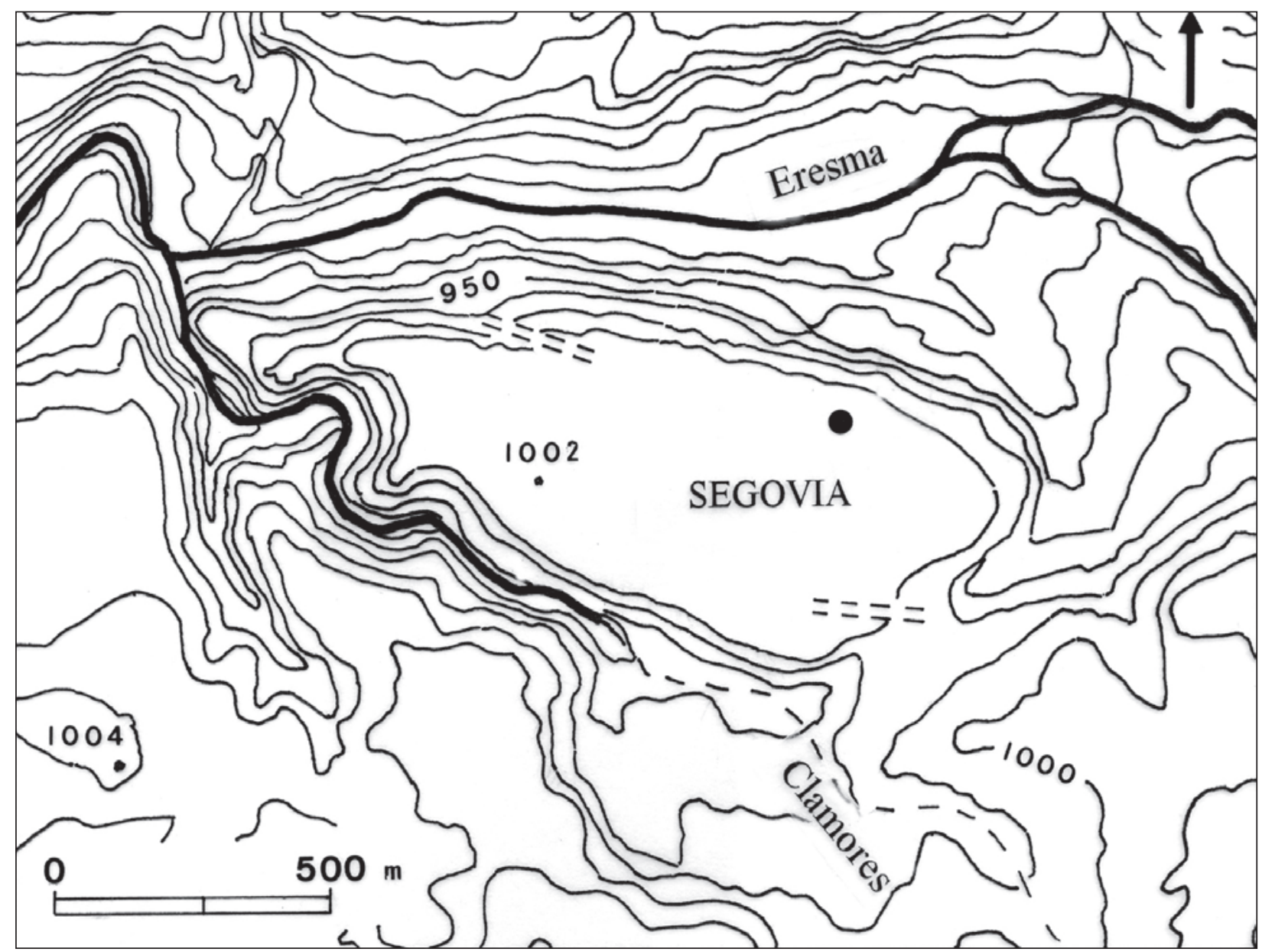

Figura 1. Topografía de la ciudad de Segovia, con el lugar donde se localizaba el antiguo Colegio de los Hermanos Maristas (punto negro). Calco de la C. M. E., Escala 1:25.000, hoja n 35-37, "Segovia”, ed. I. G. E., 1990.

2 Sobre estos aspectos, véanse Barrio Martín 1999: 94-96, fig. 45; Blanco García, 1999: 83-85, fig. 2; Id., 2002: 175-178; Id., 2006: 53-49, fig. 2. 
dad prerromana y únicamente en algunos puntos del casco antiguo han podido ser rescatadas evidencias materiales de aquellos siglos, sobre todo de tipo cerámico ${ }^{3}$. Bien es cierto que en las últimas décadas hemos ido conociendo algunos datos interesantes del enclave arévaco de Segovia, pero no lo es menos que siguen siendo muy escasos y verdaderamente no hacen justicia a la importancia que hubo de alcanzar entre los siglos III y I a. C., cuando ya se había convertido en un auténtico oppidum.

Uno de esos puntos en el que se recuperó un conjunto relativamente importante de restos celtibéricos, aunque también romanos, es el solar del antiguo Colegio de Los Hermanos Maristas, situado cerca del borde septentrional del peñasco segoviano (Figura 1). Cuando en 1974 se procedió a hacer el vaciado del mismo para construir un nuevo edificio, comenzaron a aparecer gran cantidad de materiales arqueológicos, sobre todo fragmentos de cerámica. Debido a que se encontraban muy revueltos y mezclados con abundantes cenizas y restos de faunas consumidas, se interpretó el depósito como una enorme escombrera de época antigua (Zamora Canellada, 1975: 35; Id., 1976: 11). Muchos de esos materiales fueron a parar, afortunadamente, al Museo Provincial, pero otros terminaron en varias escombreras de los alrededores de la ciudad, parte de los cuales pudieron ser recuperados pero otros quedaron irremediablemente perdidos para la investigación. Los únicos fragmentos cerámicos que por aquellas fechas se dieron a conocer fueron los recogidos entre las tierras de las mismas obras (Zamora Canellada, 1975), y los que se recuperaron durante el cribado de las que se llevaron al polígono de "El Palo", situado a unos doce kilómetros de Segovia, para distribuirlas por jardines de la zona (Id., 2006: 160, n. 196). Estos últimos dieron lugar a dos pequeños artículos. Uno firmado por Ortega

3 Un estudio de conjunto de todos estos materiales cerámicos, bien ilustrados y abordado con criterios actuales, sería de capital importancia para poder detallar aspectos cronológicos, pues en la actualidad es factible hacer precisiones que cuando se publicaron la mayor parte de ellos no eran posibles y que siguen resultando arriesgadas de hacer a partir de la documentación gráfica aportada entonces. Por otra parte,
Puente y González Zamora (1975) y el otro por Ruano Ruiz (1976). Ambos son trabajos cuya deficiente documentación gráfica les hace poco aprovechables para un análisis detallado de los materiales, y en el caso del primero de ellos, de no ser por el fragmento pintado con un zoomorfo en perspectiva cenital -curiosamente bien orientado en el dibujo que se aporta pero mal en la fotografía debido a que erróneamente fue interpretado como figura antropomorfa, y a la que más tarde se le añadieron apreciaciones sobre su anatomía igualmente poco afortunadas por parte de $\mathrm{M}$. R. Lucas (1981: 269 n. 105)-, probablemente hubiera pasado desapercibido para la investigación.

Pues bien, entre estos materiales, y no sabemos bien la razón por la que quedaron inéditos, pues son de un indudable interés, se encontraban los tres fragmentos que han motivado estas páginas con las que modestamente homenajeamos a nuestro maestro $\mathrm{y}$ compañero Manuel Bendala.

El primero de ellos es un fragmento de cabeza y cuello de caballo (Figuras 2 y 3 ) que ha sido modelada en cerámica muy bien tamizada -característica de las denominadas "producciones cerámicas singulares" celtibéricas-, y porta el número de inventario del Museo Provincial A-12354 (Zamora Canellada, 2006: 69, fot. sup. de p. 59). Fue recuperado durante el cribado de las tierras llevadas al referido polígono de "El Palo". Tiene $60 \mathrm{~mm}$ de longitud máxima, $42 \mathrm{~mm}$ de altura y $22 \mathrm{~mm}$ de anchura máxima. La figura se encuentra fragmentada tanto en la mitad del cuello como en la zona de las orejas, de las cuales sólo se conserva su inicio. A sus superficies, muy bien alisadas, se les dio un acabado a espátula, como evidencian las marcas planas que de la misma han quedado. Resulta un poco extraño que no se hayan indicado los ojos, ni mediante sencillas impresiones ni con pintura, salvo que los hubiera teni-

siempre hemos tenido la sensación de que lo publicado ha sido sólo una selección de lo más vistoso, pero que muchos otros materiales interesantes han quedado inéditos. Esta es la imagen que dan, por ejemplo, los publicados por Molinero (1971: 70, lám. CXV, fig. 1, 2610 (5-1 a 5-6) y fig. 2, $2610(5-7$ a $5-16)$ 


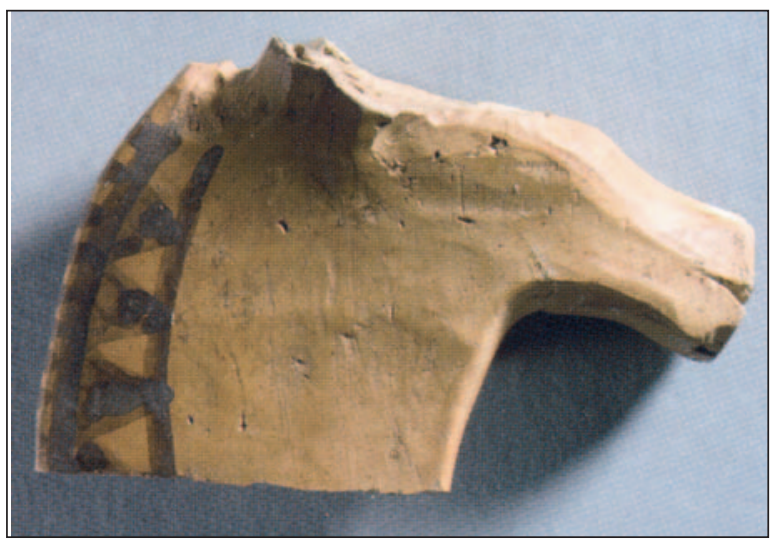

Figura 2. Cara derecha de la figura del caballo (Zamora Canellada, 2006. Foto: M. Blanco).

do pintados pero se hubieran perdido, aunque restos siempre suelen quedar y aquí no son visibles. El morro, plano y circular, sí que muestra los orificios nasales -obtenidos por impresión de una punta de sección circularasí como la boca, realizada mediante una incisión profunda y casi recta que se prolonga con distinta longitud en los laterales del morro. Las crines aparecen indicadas con pintura marrón oscura pero no se representan del mismo modo a uno y otro lado del cuello: las del lado izquierdo son una serie de trazos sinuosos de longitudes variables y las del derecho aparecen esquematizadas en forma de triángulos o dientes de lobo enmarcados entre dos líneas que recorren longitudinalmente la verticalidad del cuello. Una peculia- ridad más que posee esta cabeza equina es que posee dos orificios en la parte alta de la frente como si hubiera tenido un aplique o un añadido. Además de éstos, tiene un orificio que cala por completo la pieza, en vertical, desde el centro de la rotura de la base hasta la zona de las orejas, aunque en esta última ya se encuentra en posición descentrada. Este detalle nos induce pensar, con cierto fundamento, que el caballo fue en origen una figura completa en la que seguramente cada una de sus partes anatómicas básicas (cabeza, cuerpo y patas) se modelaron independientemente $y$ después se ensamblaron utilizando espigas, tal vez de madera o de hueso, para asegurar la cohesión de todo el conjunto. Una vez ensamblado, y con el barro en estado semiduro, es de suponer que se cerrarían a espátula las juntas externas que quedasen entre los planos de conexión de las distintas partes anatómicas. No creemos que fuera, por tanto, la cabeza equina perteneciente a un simpulum de barro como los que se tienen constatados, por ejemplo, en la necrópolis de Palenzuela (Martín Valls, 1992, 146-147, 9, 15-17, fig. 1, Tipo IIIb) o en Numancia (Id., 1992: 148, 31), y tampoco el remate decorado de un vaso, un aplique o una de esas piezas con forma de prótomo equino que, como algunas de las numantinas, tradicionalmente han sido interpretadas como exvotos (Blanco García, 2003: 83-85, 107-108, fig. 4, 2-9 y 11-13).

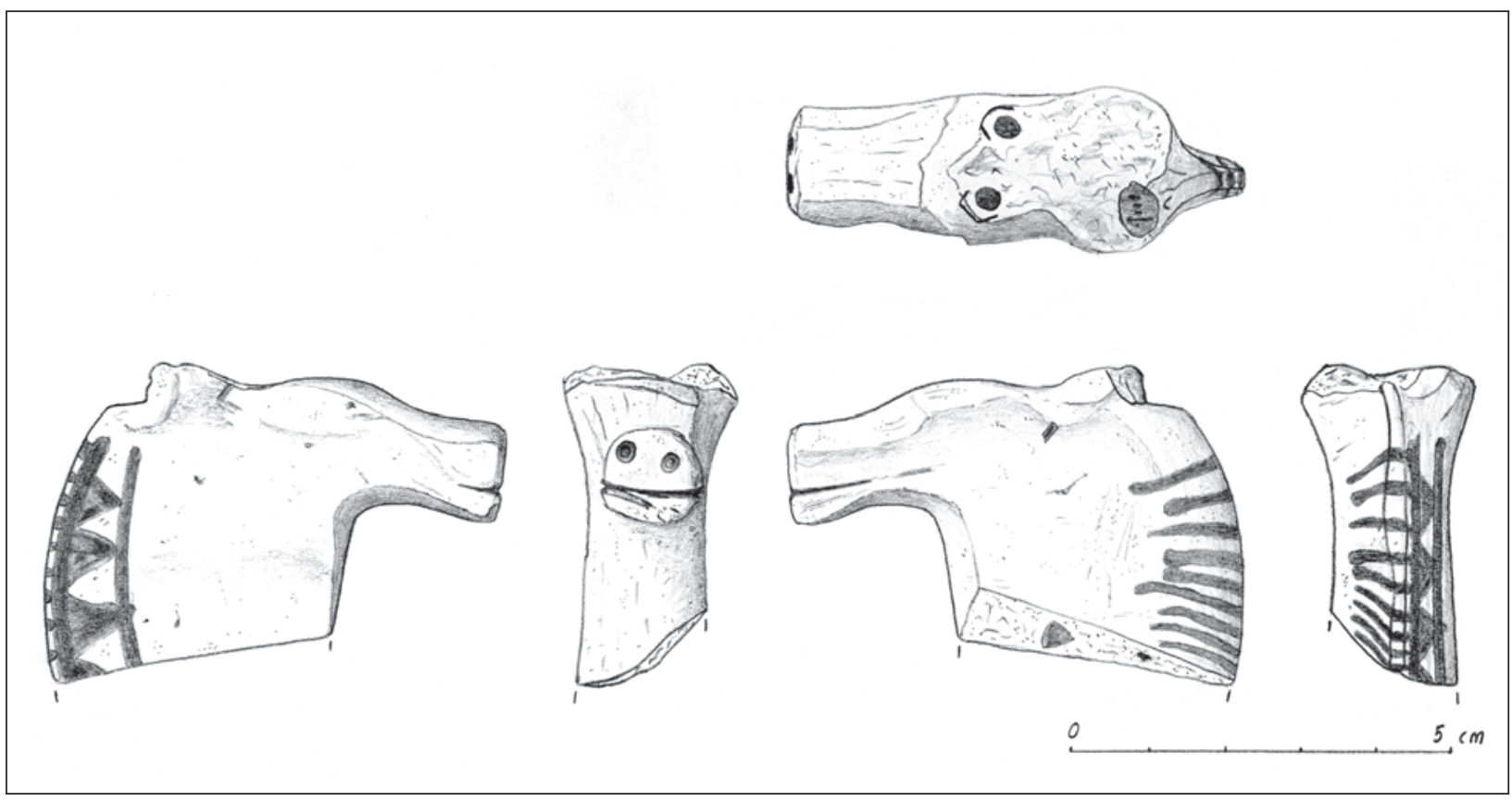

Figura 3. Desarrollo completo de la figura del caballo. 
Desconocemos la altura que pudo haber alcanzado esta figura equina cuando estaba completa así como la función para la que se fabricó. Con este tipo de piezas siempre se presenta la duda de si se trata de un sencillo juguete infantil o bien hemos de relacionarlo con las esferas social y religiosa de quienes hicieron uso de ella, pues sabido es cómo el caballo en la vida de los pueblos prerromanos peninsulares, europeos y de todo el Mediterráneo en general, gozaba de un enorme prestigio por ser uno de los símbolos predilectos del alto estatus social de su propietario y al que se le creía depositario de virtudes divinas como la bondad, la nobleza, la fidelidad, etc. (Sánchez Moreno, 1995-96; Quesada y Zamora, 2003; García-Gelabert y Blázquez Martínez, 2006). En la Céltica el caballo tiene una relación directa con algunas de las más importantes divinidades: con Epona sobre todo, representada siempre junto a caballos (Linduff, 1979; Salinas, 1984-85: 96-97; Marco Simón, 1994: 337; Green, 1989: 16-24; Ead., 1997: 14; Alfayé, 2003: 82-86; Ead., 2009: 349-352), y considerada

4 Esta es, por ahora, la única imagen de guerrero ecuestre en cerámica celtibérica que se conoce en Segovia. Decimos esto porque en 1888 el anticuario y numísmata Aloïs Heiss publicó en París una noticia relativa a un Plat Celtibérien en terre cuite, découvert à Ségovie -que fue extractada en el Boletín de la Real Academia de la Historia (14, 1889, 271272)-, en la que se indica que poseía un "...personnage armé d'une lance et de trois javelot rapelle le guerrier qu'on voit au revers des bronzes de Ventipo." Además, refiere que tenía "...deux inscriptions circulaires en caractéres celtiberiens.", comentario que unos párrafos más adelante completa al decir que "Les lettres inscrites sur ce plat son très saillantes; elles appartiennent à l'écriture ibérienne des médailles autonomes de l'Espagne et des inscriptions lapidaires de la même époque". Podría ser asumible que los caracteres que se reconocieron fueran ibéricos, pero lo que no corresponde en absoluto a la cerámica celtibérica es que sus superficies estuvieran recubiertas de barniz negro, estuviera decorado con palmetas y tuviera nada menos que medio metro de diámetro. El barniz negro y las palmetas nos hacen pensar en que realmente podría tratarse de cerámica campaniense, algunos de cuyos platos, fuentes y grandes cuencos tienen un abultado umbo central (Morel, 1981: 1331a 1, 1646c 1, 1648a-d, 1752a 1, 1753a 1, y también los de la serie 2170). En nada repugna esto con la existencia de los grafitos ya que muchas de las campanienses recuperadas en los territorios ibéricos cuentan con textos y grafitos en la escritura propia de quienes los habitaron. Sin embargo, estas grafías siempre son incisas, nunca "en relieve", detalle éste que, por otra parte, supondría que se han fuente de prosperidad y abundancia (Mackintosh, 1995: 29), pero también con el politécnico y polifuncional Lug (Marco Simón, 1990: 165; Meid, 1993-1995: 350353; Id., 1999: 493-494). Con la divinidad pancéltica citada en último lugar comparte su carácter solar, del que es símbolo también la svástica, frecuentemente asociada a imágenes de équidos, como se puede ver en algunas cerámicas numantinas (Wattenberg Sanpere, 1963: 214, lám. II, 1-1193, 2-1194, lám. III, 1-1195, 2-1196, lám. IV, 1-1197, 2-1198).

Otro fragmento cerámico de no menor interés que el anterior es el perteneciente a un vaso celtibérico en el que con pintura ocre oscura se ha pintado un jinete con lanza (Figuras 4-6) $)^{4}$. De la imagen, que en origen con toda probabilidad fue un guerrero ecuestre completo y que incluso pudo haber formado parte de una escena compleja con otras imágenes, sólo se conserva parte del cuello del caballo, una minúscula porción de lo que parece ser el extremo inferior interno del morro, el brazo izquierdo del jinete y parte

realizado durante la fabricación del plato en cuestión, lo cual nos conduce bien a que pudiera tratarse de una imitación peninsular de campaniense con elementos indígenas añadidos, que sí existen sobre todo en la zona de Cataluña, bien a algunas producciones de campaniense, como las de "Nikia-Iôn", decoradas con estampillas en las que aparecen textos dispuestos en círculo pero escritos en griego (Principal-Ponce, 2008). ¿Podría haberse confundido el griego con el ibérico? Es difícil creer que Heiss hubiera cometido tal error con lo acostumbrado que estaba a ver "monedas autónomas". El motivo ecuestre, por otro lado, es desconocido en la decoración de la cerámica campaniense.

Sí hay textos en relieve, palmetas impresas e imágenes complejas (Rigoir et Meffre, 1973), incluso algunas de ellas ecuestres y relacionadas con la ideología cristiana, en fuentes y platos de sigillata gris y negra narbonenses de los siglos IV y V d. C. cuyos excelentes engobes bien podrían ser a los que se refiere el dato del barniz negro. Pero los textos son ya en alfabeto latino y Heiss tampoco hubiera confundido nunca estas grafías con las griegas o con las supuestamente ibéricas, impensables, por otra parte, en materiales tardoantiguos. En resumen, es todo un enigma lo referente al Plat Celtibérien de Heiss pues, de tratarse de una cerámica original y no de una falsificación, que todo es posible, y más en aquella época, hay elementos extraños a la campaniense, a la cerámica de lujo tardoantigua y, con más contundencia, a la celtibérica, por lo que lo mejor es, mientras no se localice, y esto es poco menos que imposible ya, no considerarlo en ninguno de estos tres campos de investigación. 


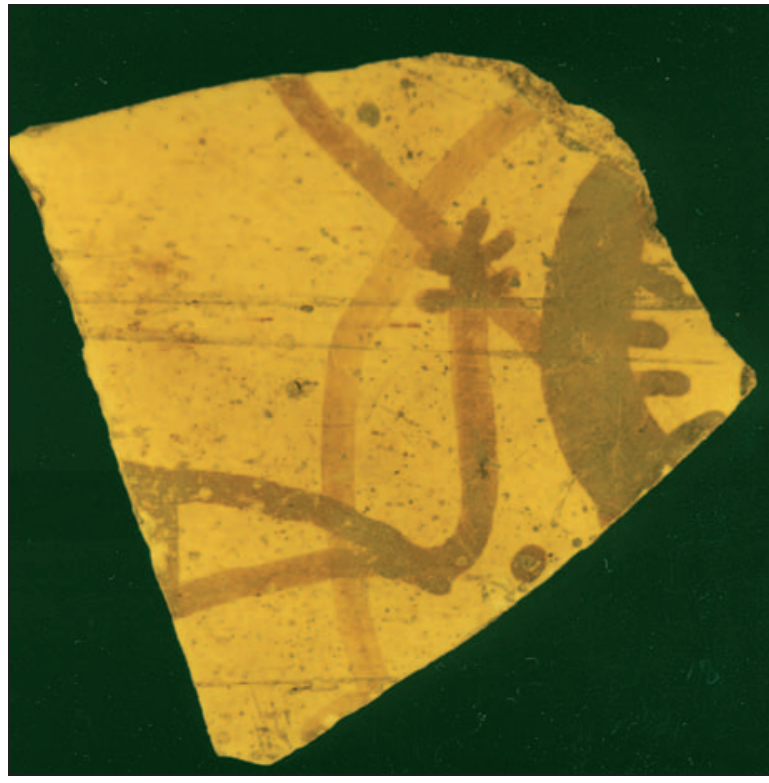

Figura 4. Fragmento de vaso en el que se ha pintado un guerrero ecuestre con lanza.

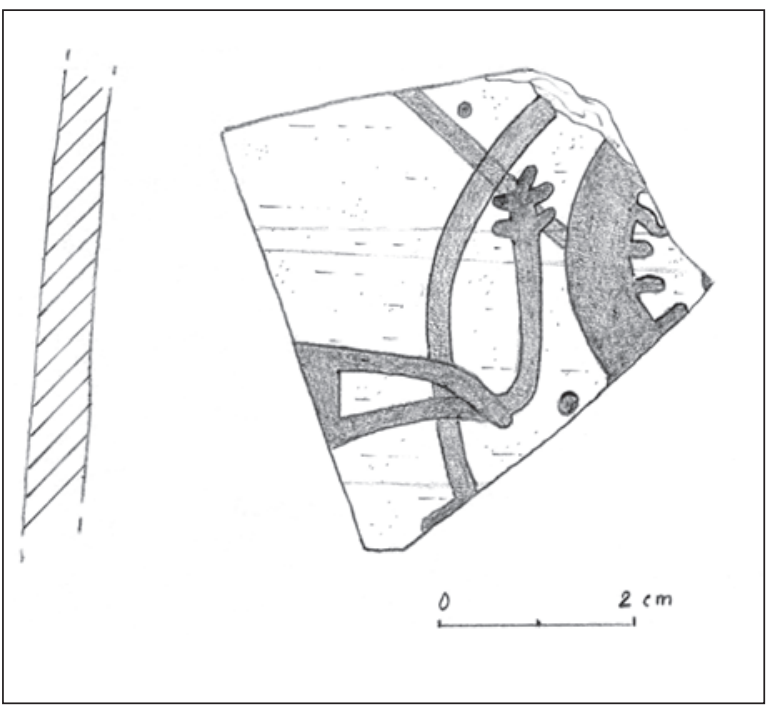

Figura 5. Dibujo del fragmento de vaso con guerrero ecuestre pintado.

del astil de la lanza que éste sostiene. Al desconocer las dimensiones del arma de ataque, no podemos saber si verdaderamente se trataba de una lanza o de una jabalina, siempre de menores dimensiones esta última. A pesar de ello, si consideramos que en la Hispania céltica los jinetes que nos muestra la iconografía van armados predominantemente con lanza pesada para la carga, a diferencia de los que aparecen en la cultura ibérica, propios de una caballería ligera armada generalmente con jabalina, lo más lógico es pensar que el arma que porta el eques segoviano fuera una lanza.

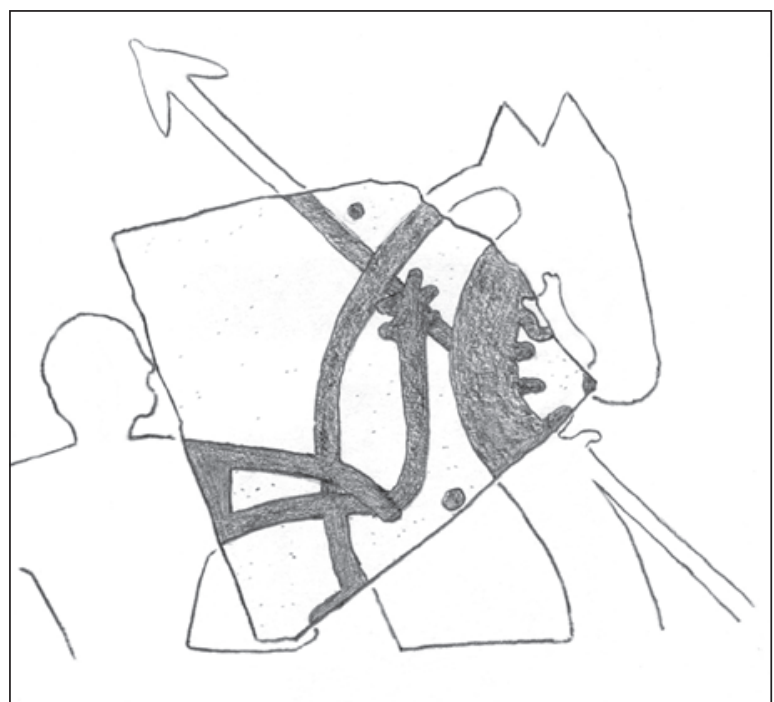

Figura 6. Restitución aproximada e hipotética de las partes periféricas de la imagen del guerrero ecuestre.

El cuello del équido muestra las crines colgando no de la parte posterior del mismo, es decir, en sentido contrario a la marcha, como es lo habitual, sino de la delantera, lo cual constituye una rareza. Este detalle, aparentemente intrascendente pero único en la iconografía equina celtibérica e incluso ibérica, abre la posibilidad de que en lugar de tratarse de un error del pintor, como inicialmente pudiera parecer, quizá lo que se haya querido representar es el caballo haciendo una cabriola, y en este sentido nos vienen a la memoria las que habitualmente realizaban los equites romanos en torno a la pira funeraria de sus generales durante la ceremonia de la decursio equitum -recuérdense, por ejemplo, los funerales de Sila (Appiano, $B C$, I, 106, 500)- o las de los guerreros hispanos en torno a la de sus jefes militares, y aquí hemos de recordar necesariamente los funerales de Viriato descritos por Appiano (Iber. LXXI) y Diodoro Sículo (XXXIII, 21). Salvando las distancias cronológicas y artísticas, las crines han sido pintadas de manera parecida a como el pintor neoclásico francés Jacques Louis David pintó las del caballo de Bonaparte durante el paso de Los Alpes (Figura 7). A favor de esta interpretación de la imagen segoviana es muy significativo también que, si tenemos en cuenta la horizontalidad de las huellas del torno y restituimos, manteniendo las proporciones, evidentemente, las partes perdidas inmediatas a los trazos conservados (Figura 6), el cuello 


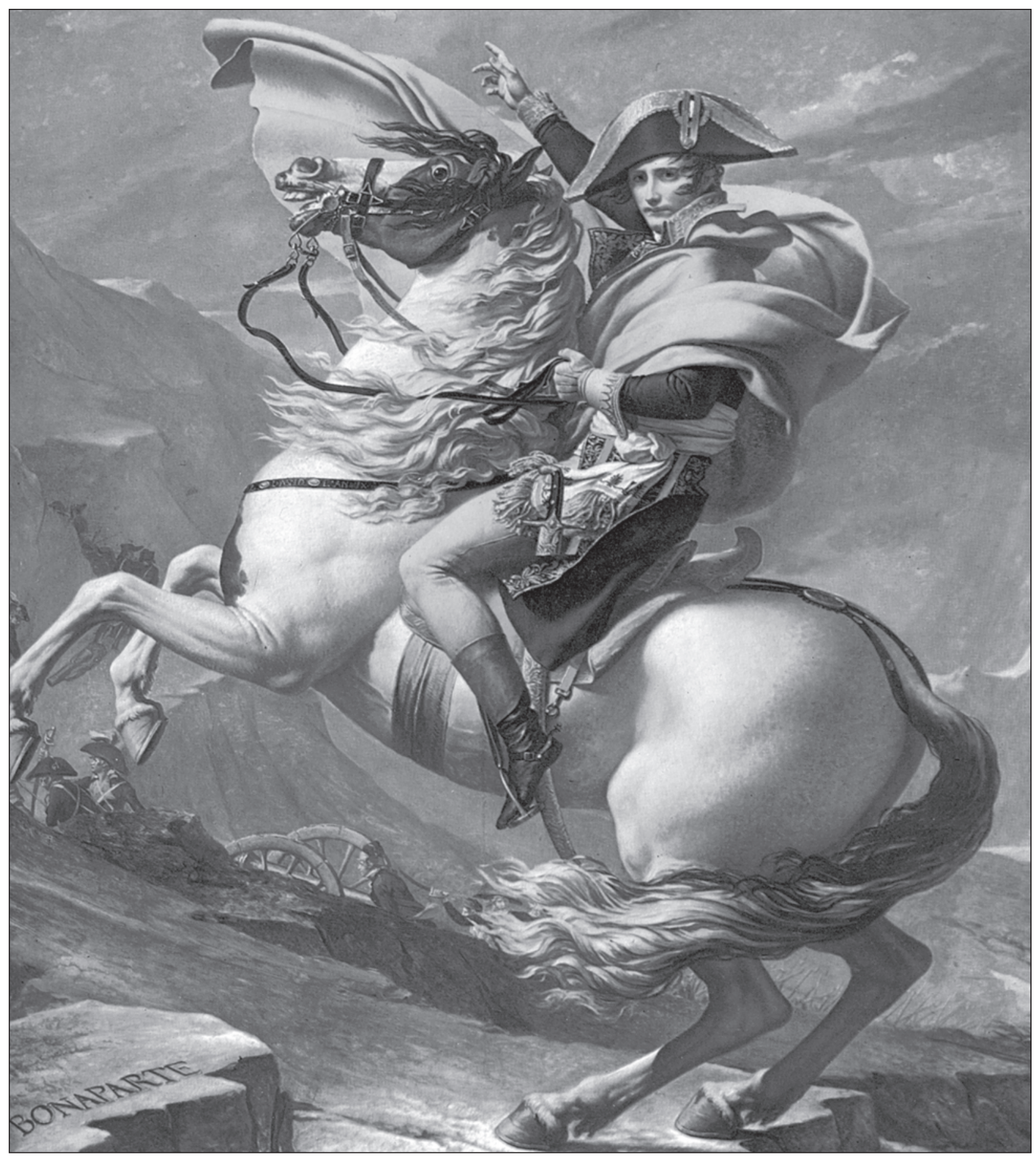

Figura 7. Bonaparte atravesando Los Alpes (óleo de Jacques Louis David, 1804).

y la cabeza del équido se sitúan a mayor altura que la cabeza del jinete, circunstancia ésta que no se produce cuando el caballo va marchando -y no hay más que comprobarlo en la iconografía monetaria, por ejemplo- pero sí cuando está de manos, aunque no ocurre lo mismo en el caso del referido cuadro de David, donde el artista pintó a un Bonaparte de tamaño intencionadamente exagerado respecto al del caballo para conseguir el ensalza- miento de la figura del político y militar, pues sabida es la baja estatura que tenía.

El brazo del jinete, realizado con doble línea y el interior sin pintar, termina en una mano en la que aparecen bien indicados los cinco dedos extendidos, no empuñando la lanza que sostiene, aunque esto es lo habitual, como puede observarse, por ejemplo, en el guerrero con lanza en mano de la jarra del Castillo de Ocenilla (Lorrio, 1997: 190, fig. 
$79,11)$. La lanza ha sido representada no en posición de ataque (en ristre), tal como nos muestran los reversos de las monedas celtibéricas o varias de las estelas discoidales celtibérico-romanas, sino levantada en diagonal, algo que es muy poco frecuente en el ámbito meseteño pero que paralelos, aunque de momentos ya romanos, no faltan, como se puede ver en la estela de Contreras (Abásolo y Marco, 1995: 339, lám. VI, 2) o en una de las de Lara de los Infantes (Abásolo y Marco, 1995: 329, lám. IV). Lo más probable es que hubiera sido pintada con la punta hacia arriba, tal como la encontramos en numerosas imágenes vasculares de guerreros a pie de Numancia o la citada de Ocenilla. Sin embargo, no podemos descartar que la punta hubiera estado pintada en el extremo inferior del astil, al modo como aparece en muchas escenas cinegéticas pintadas en vasos ibéricos, en cuyo caso, bastante improbable a nuestro parecer, cabría la posibilidad de que la escena se completara con una imagen del animal objeto de la caza (jabalí, cérvido, zorro, etc.) situado en la parte delantera inferior del caba1lo. En el ámbito celtibérico la representación del jinete con la lanza dispuesta en la posición que nos muestra el guerrero segoviano es excepcional, lo cual pudiera incluso tener una lectura cronológica. Con esto último queremos decir que si consideramos que el jinete con la lanza en ristre de los reversos de las acuñaciones celtibéricas aunque comienza a representarse en la segunda mitad del siglo II a. C. no se generaliza hasta la transición del siglo II al I a. C. y el primer cuarto de este último (Burillo Mozota, 1995: 170), la imagen segoviana podría haber sido pintada en momentos algo anteriores a dicha transición. Esto es sólo una posibilidad que hemos de contemplar pero que es poco probable que así fuera de considerar que en la iconografía prerromana meseteña de finales del siglo II a. C. $\mathrm{y}$ todo el siglo siguiente coexistieron distintas maneras de representar las imágenes figurativas. Esta es la razón por la cual los intentos que hasta ahora se han llevado a cabo para establecer una evolución de la imaginería celtibérica han dado pocos frutos.

Volviendo a los detalles anatómicos, si consideramos el trazo doble del brazo y la similitud que presenta con imágenes antropomorfas celtibéricas bien conocidas como, por ejemplo, la del guerrero numantino tendido en el suelo que presumiblemente está siendo devorado por un buitre (Figura 8), o con los mismos guerreros ecuestres de las estelas, es indudable que el torso del guerrero segoviano se pintó en posición frontal y la pierna visible al espectador -la derecha, pues la izquierda la taparía el cuerpo del caballo y como mucho aparecería tras él el pie izquierdo-, de perfil. Por otra parte, al ser el brazo izquierdo de doble línea con el interior sin pintar, es de suponer que el derecho fuera de ejecución similar, pues una de las más destacadas características que presenta la iconografía celtibérica, tanto abstracta como figurativa, es su acusada simetría.

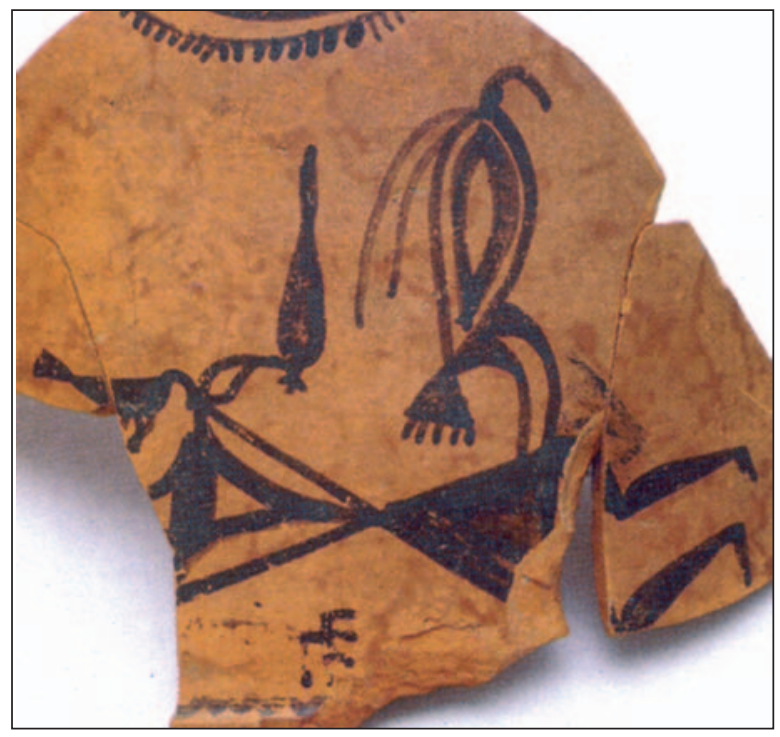

Figura 8. Fragmento cerámico de Numancia con guerrero tendido en el suelo presuntamente siendo devorado por un buitre (Sopeña, 2005. Foto: A. Plaza)

Por similitud con imágenes de guerreros ecuestres de los ámbitos vettón e ibérico, y estamos pensando en el guerrero ecuestre del poblado de La Coraja, en la cacereña Aldeacentenera (Cabello Caja, 1991-92: 106, fig. 7), en la estela pétrea de El Palao, de Alcañiz (Marco Simón, 1976: 76, fig. 2; Benavente Serrano, Marco Simón y Moret, 2003: 235, fig. 3; Blázquez Martínez, 2005: 228, fig. 4) (Figura 9), y en la tinajilla $156 \mathrm{del}$ departamento 95 de Llíria (Olmos, Tortosa e Iguácel, 1992: 49, 1; Kurtz, 1992: 213, fig. 10; Aranegui, Mata y Pérez, 1997: 62, fig. II, 10), por citar sólo unos ejemplos socorridos por bien conocidos, lo más probable es que en 


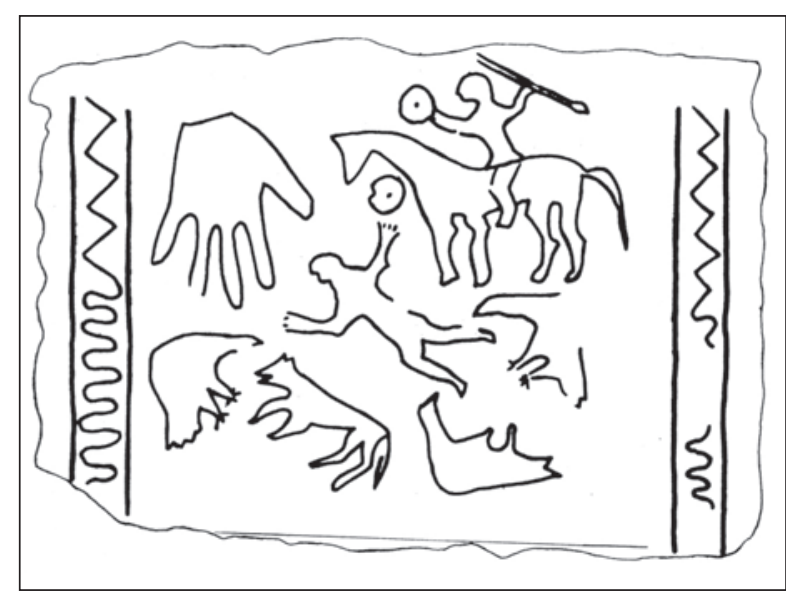

Figura 9. Detalle del guerrero ecuestre de la estela de El Palao (Alcañiz, Teruel).

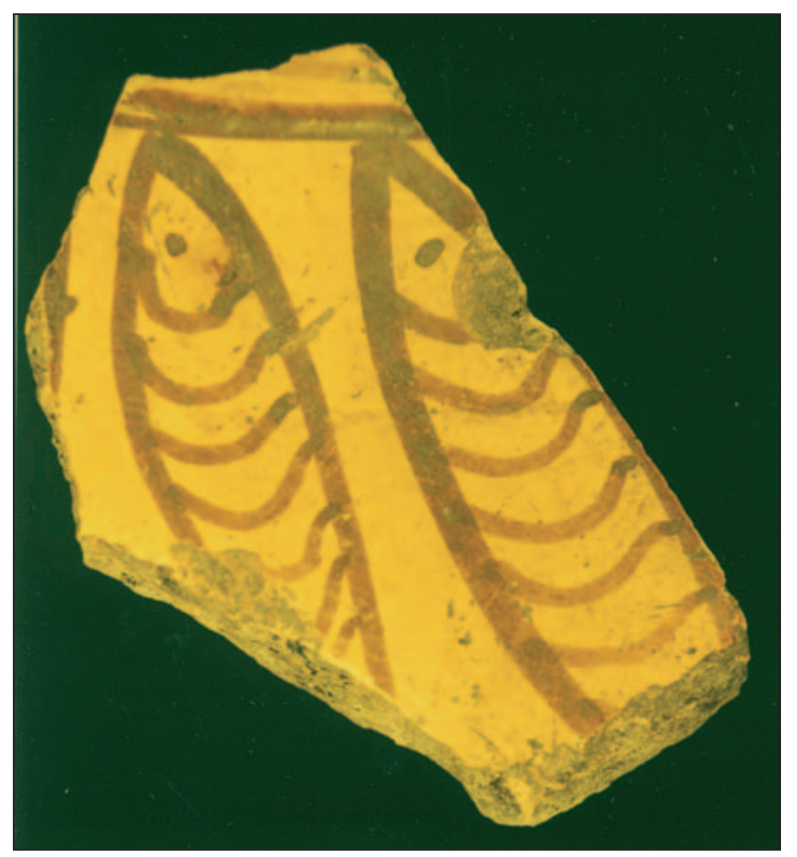

Figura 10. Fragmento de vaso con peces pintados dispuestos en posición vertical.

la otra mano portase un scutum que, considerando la celticidad de las poblaciones meseteñas, seguramente era circular u ovalado (Lorrio, 1997: 194; Sanz Mínguez, 2002: 124), más que rectangular. Y aquí vemos de nuevo otra peculiaridad del jinete segoviano, pues lleva la lanza en la mano izquierda y el escudo en la derecha, cuando lo corriente es justamente al revés, tal como se puede observar, por ejemplo, en las referidas estelas discoidales de Contreras y Lara de Los Infantes. A pesar de ello, no es un unicum esta forma de representarlo porque el que aparece en la estela de El Palao también lleva en su mano izquierda una jabalina, lo mismo que algunos de los guerreros partícipes en combates entre infantes armados con escudo y jabalina (Sanz Mínguez, 1997: 87 y 445-446, fig. 77), si bien a veces esto se representa así por simples razones de simetría, como puede comprobarse en varios ejemplos (Lorrio, 2008: 258, fig. 2, 2 y fig. 3).

Respecto a la cabeza del guerrero, seguramente pintada de perfil, como es lo habitual en la iconografía prerromana peninsular, poco podemos decir porque las posibilidades que nos presentan los materiales con los que podría paralelizarse son muchas: que fuera un simple círculo (Wattenberg Sanpere, 1963: 209, 1115, lám. X, 5-1240), que se hubiesen pintado algunos detalles como el ojo, la boca, la nariz o incluso los cabellos (Cabello Caja, 1991-92: 106, fig. 7; García Merino, 2005: 180, fig. 3), que fuera desnuda o estuviera cubierta con casco, tal como muestran muchos de los jinetes de las acuñaciones así como algunos guerreros de a pie, etc.

En resumen, conjuntando todos estos elementos, y de haber sido las partes perdidas como nosotros suponemos que fueron siguiendo los paralelismos más próximos iconográficamente y lógicos, esta representación ecuestre no sería la de un jinete lancero a punto de entrar en batalla, en actitud de carga, sino más bien de alardeo, de victoriosa celebración o incluso de reto, evidenciada ésta a través de la representación de las crines en la parte delantera del cuello, de la lanza levantada y de la posición sensiblemente más alta de la cabeza del caballo respecto de la del jinete. Pocas posibilidades creemos que existen de que se tratase de una escena de caza al estilo de las que nos muestran las pinturas vasculares ibéricas porque en el mundo celtibérico este tipo de narraciones, míticas o reales, no parece que arraigaran, y únicamente en algunas estelas en las que el jinete aparece como heros equitans está presente, algo por ahora inexistente en soporte cerámico. A diferencia de otras representaciones ecuestres vasculares meseteñas en las que la imagen ha sido tratada con gran economía de rasgos, como puede observarse, por ejemplo, en las que fueron pintadas en sendos vasos hallados en el cas- 
tro vettón de Las Cogotas (Cabré Aguiló, 1930: lám. LX), la segoviana es más realista, aunque está dentro del habitual esquematismo que poseen las realizaciones artísticas de las poblaciones de filiación céltica.

La tercera imagen se encuentra pintada en un fragmento de vaso celtibérico, quizá una jarra, perteneciente al hombro. Se trata de dos peces casi completos que parecen haber estado pintados dentro de una metopa, pues en la parte izquierda del fragmento aparece un trazo totalmente vertical que no corresponde a un tercer pez, sino al límite izquierdo de la misma. Ambos peces están dispuestos en posición casi vertical, con las cabezas hacia arriba, y el interior relleno de líneas sinuosas transversales pintadas a distancias regulares (Figuras 11 y 12). Si los peces están entre los animales más pintados tanto en las cerámicas celtibéricas como en las vacceas (Romero Carnicero, 1976: 149 y 153; Blanco García, 1995: 217-218, fig. 2), su representación en vertical es muy poco frecuente, pues, salvo contadas excepciones, como algunos recientemente dados a conocer de Padilla de Duero (Delgado Lozano, 2008: fig. 5), o aquellas otras en las que la figura del pez es utilizada como icono asociado a otras imágenes (p. ej., Wattenberg Sanpere, 1963: 220, n 1288 , lám. 13, 13-1288; Romero Carnicero, 1988: 197), lo habitual es hacerlo en horizontal o levemente inclinados, dirigiéndose bien hacia la

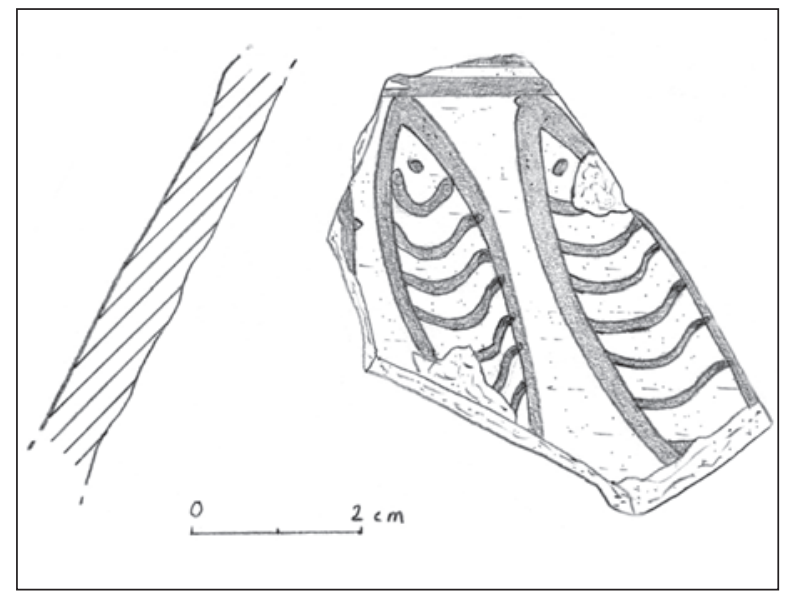

Figura 11. Dibujo del fragmento de vaso con peces pintados. izquierda o bien hacia la derecha, y a veces asociados a motivos geométricos alusivos a su medio natural, al agua (ondas, espirales, eses sencillas y dobles, etc.).

Dicho todo esto, hemos de concluir con algunos aspectos que se pueden poner en relación con las imágenes presentadas. La mayor parte de la cerámica celtibérica recuperada en Segovia hasta ahora, incluidos estos tres documentos iconográficos, pertenece a los siglos II y I a. C., lo que nos está indicando que esta es la fase de máximo desarrollo demográfico y económico de la ciudad y que, de paso, explica la importancia que llegará a alcanzar durante el Alto Imperio. Como la de cualquier otra ciudad celtibérica de esos siglos, la sociedad de Segovia debió de estar muy jerarquizada y profundamente impregnada de militarismo, de todo lo que tuviera que ver con la guerra como mecanismo de enriquecimiento y de promoción social, por lo que hubo de estar dirigida políticamente por una élite guerrera aristocrática que, a juzgar por el tamaño que parece pudo haber alcanzado, dispondría de un numeroso cuerpo de caballería, de nobiles equites. ${ }^{5}$ Estas élites ecuestres urbanas serían las que principalmente formarían parte de los ejércitos cartagineses y romanos en calidad de mercenarios, tal como en ocasiones refieren los autores clásicos, lo que constituiría una jugosa fuente de ingresos al tiempo que contribuiría al reforzamiento de su poder en sus respectivas ciudades. Que Segovia hubo de disponer de un cuerpo de caballería importante numéricamente y bien armado, cuya principal responsabilidad era la defensa de la ciudad por ser los mejor preparados para la guerra, lo reflejan indirectamente las propias fuentes, pues Livio (Fragmenta. XXII, 13) refiere cómo en el año 76 a. C., en el contexto de las Guerras Sertorianas, Marco Mario envió al prefecto de caballería Cayo Insteyo a Segovia y al país de los vacceos -presumiblemente a ciudades vacceas cercanas a Segovia como Cauca, Pintia o Septimanca, no a Cuéllar, que en esos momentos ya estaba deshabitada (Barrio Martín, 1993: 212)-, para reclutar fuerzas de caballería (Capalvo, 1996: 71-72). Este es un

Ciprés, 1993: 88-116; Ead., 2002; Almagro-Gorbea, 1997 y 2005; Almagro-Gorbea y Torres Ortiz, 1999: 91 y ss.
5 Sobre el perfil social de estas clases, así como sobre su mentalidad y sus estrategias de guerra, véanse entre otros, 
texto magnífico que en combinación con la cabeza de caballo y el jinete lancero pintado que aquí estudiamos reflejan en conjunto la importancia que en el oppidum de Segovia tenía dicho cuerpo y la clase social de la que formaba parte, que, en definitiva, era la que regía la ciudad en su fase prerromana más avanzada. Y aún podría decirse algo más: viendo el énfasis que las fuentes clásicas ponen en la existencia de jefes militares en las sociedades indígenas, algunos de los cuales mencionan, como Viriato, Retógenes, Olíndico, Hilerno, etc., es de suponer que Segovia hubo de contar también con los suyos.

Al desconocer la entidad demográfica que pudo haber alcanzado Segovia a finales de la Edad del Hierro, resulta imposible hacer estimaciones relativas al volumen de sus clases rectoras $\mathrm{y}$, por tanto, del que pudo haber representado su fuerza de caballería. Y tampoco son viables las estimaciones tomando como referencia las cifras que los autores clásicos dan para otras ciudades meseteñas contemporáneas de extensión similar a Segovia porque en unas ocasiones esas cifras son manifiestamente exageradas -como en el caso de Segeda, en la que se citan 5000 jinetes para el año 153 a. C. (Appiano, Iber., 45)- y en otras refieren la caballería local más la que ha huido de otras ciudades amenazadas o destruidas -como ocurre con los 2000 jinetes de Intercatia en el año 151 a. C. (Appiano, Iber., 53).

Mucho es lo que aún desconocemos de Segovia celtibérica, pero poco a poco los trabajos arqueológicos que en la ciudad se realizan van aportando pequeños detalles que nos la acercan de manera más viva y real.

\section{BIBLIOGRAFÍA}

ABÁSOLO, J. A. y MARCO, F., 1995: “Tipología e iconografía en las estelas de la mitad septentrional de la península Ibérica", en F. Beltrán (ed.) Roma y el Nacimiento de la Cultura Epigráfica en Occidente, 327-359. Zaragoza.

ALFAYÉ, S., 2003: "La iconografía divina en Celtiberia: una revisión crítica", Archivo Español de Arqueología, 76, 77-96. Madrid.

- 2009: Santuarios y rituales en la Hispania céltica. BAR, Int. Sers., 1963. Oxford.
ALMAGRO-GORBEA, M., 1997: “Guerra y sociedad en la Hispania céltica", en La Guerra en la Antigüedad. Una Aproximación al Origen de los Ejércitos en Hispania. Catálogo de la Exposición (Madrid, 1997), 207-221. Madrid.

- 2005: "Ideología ecuestre en la Hispania prerromana”, Gladius, XXV, 151-186. Madrid.

ALMAGRO GORBEA, M. y TORRES ORTIZ, M., 1999: Las fibulas de jinete y de caballito. Aproximación a las élites ecuestres y su expansión en la Hispania céltica. Institución Fernando el Católico. Zaragoza.

ARANEGUI, C., MATA, C. y PÉREZ, J., 1997: Damas y caballeros en la ciudad ibérica. Las cerámicas decoradas de Llíria (Valencia). Madrid.

BARRIO MARTÍN, J., 1993: "Estratigrafía y desarrollo poblacional en el yacimiento prerromano de la Plaza del Castillo (Cuéllar, Segovia)", en F. Romero, C. Sanz y Z. Escudero (eds.) Arqueología Vaccea. Estudios sobre el Mundo Prerromano en la Cuenca Media del Duero, 173-212. Valladolid.

BENAVENTE SERRANO, J. A., MARCO SIMÓN, F. y MORET, P., 2003: “El Palao de Alcañiz y el Bajo Aragón durante los ss. II y I A. C.”, Archivo Español de Arqueología, 76, 231-246. Madrid.

BLANCO GARCÍA, J. F., 1995: “Representaciones figurativas en la cerámica celtibérica pintada de Cauca y el castro de la Cuesta del Mercado", en V. O. Jorge (coord.) $1^{o}$ Congresso de Arqueología Peninsular. Actas V (Trabalhos de Antropología e Etnología, 35, 1), 213-232. Porto.

- 1999: "Recursos hídricos en los oppida del occidente de la provincia de Segovia: el corredor del Eresma", en F. Burillo (coord.) IV Simposio sobre Celtíberos. Economía. Institución Fernando el Católico, 81-87. Zaragoza.

- 2001: "La numismática antigua segoviana en la bibliografía. Comentarios", Numisma, LI ( ${ }^{\circ}$ 245), 115-138. Madrid.

- 2002: “Agua, municipalidad y propaganda política en Segovia romana”, Lancia, 4, 175-189. León.

- 2003: “Iconografía del caballo entre los pueblos prerromanos del centro-norte de Hispania”, en F. Quesada y M. Zamora (eds.) El Caballo en la Antigua Iberia. Estudio sobre los équidos en la Edad del Hierro. Real Academia de la Historia. Biblioteca Archaeologica Hispana, 19, 75-123. Madrid. 
- 2006: "El paisaje poblacional segoviano en época prerromana: ocupación del territorio y estrategias de urbanización", Oppidum. Cuadernos de Investigación, 2, 35-84. Segovia.

BLÁZQUEZ MARTÍNEZ, J. M., 2005: “Dioses celtibéricos”, en A. Jimeno (com.) Celtíberos. Tras la Estela de Numancia. Catálogo de la Exposición (Soria 2005), 223-228. Soria.

BURILLO MOZOTA, F., 1995: “Celtiberia: monedas, ciudades y territorios”, en M. P. García-Bellido y R. M. S. Centeno (eds.) La Moneda Hispánica. Ciudad y Territorio. Actas del I Encuentro Peninsular de Numismática Antigua. Anejos de AEspA, XIV, 161-177. Madrid.

CABELLO CAJA, R., 1991-92: “La cerámica pintada de la II Edad del Hierro en la cuenca media del Tajo", Norba, 11-12, 99-128. Cáceres.

CABRÉ AGUILÓ, J., 1930: Excavaciones en Las Cogotas (Cardeñosa, Ávila). I, El Castro. (MemJSEA, 110). Madrid.

CAPALVO. A., 1996: Celtiberia. Un estudio de fuentes literarias antiguas. Institución Fernando el Católico. Zaragoza.

CIPRÉS, P., 1993: Guerra y sociedad en la Hispania indoeuropea. Anejos de Veleia, series minor, 3. Vitoria.

- 2002: "Instituciones militares indoeuropeas en la Península Ibérica", en P. Moret y F. Quesada (eds.) La Guerra en el Mundo Ibérico y Celtibérico (ss. VI - II a. de C.). Collection de la Casa de Velázquez, vol. 78, 135-152. Madrid.

DELGADO LOZANO, S., 2008: "Sobre las representaciones de peces en las cerámicas polícromas celtibéricas", Oppidum. Cuadernos de Investigación, 4, 13-34. Segovia.

GARCÍA-GELABERT， M. P. y BLÁZQUEZ MARTÍNEZ, J. M., 2006: “Dioses y caballos en la Iberia prerromana”, Lucentum, XXV, 77-123. Alicante.

GARCÍA MERINO, C., 2005: "Uxama Argaela", en A. Jimeno (com.) Celtíberos. Tras la Estela de Numancia. Catálogo de la Exposición (Soria 2005), 177-182. Soria.

GREEN, M. J., 1989: Symbol and Image in Celtic Religious Art. Routledge. London.

- 1997: "The Symbolic Horse in Pagan Celtic Europe: An Archaeological Perspective", en S. Davies y N. A. Jones (eds.) The Horse in Celtic Europe. Medieval Welsh Perspectives, 1-22. Cardiff.

HEISS, A., 1889: "Plat celtibérien en terre cuite, découvert à Sêgovie", Boletín de la Real Academia de la Historia, 14, 272-273. Madrid.
KURTZ, W. S., 1992: “Guerra y Guerreros en la cerámica ibérica”, en R. Olmos (com.) La Sociedad Ibérica a través de la Imagen. Catálogo de la Exposición, 206-215. Barcelona.

LINDUFF, K., 1979: "Epona: a Celt among the Romans", Collection Latomus, 38 (4), 817-837. Bruxelles.

LORRIO, A. J., 1997: Los Celtíberos. Complutum, Extra 7. Alicante.

- 2008: "El armamento vettón”, en J. Álvarez-Sanchís (ed.) Arqueología vettona. La Meseta Occidental en la Edad del Hierro. Zona Arqueológica, 12, 252-274. Alcalá de Henares.

LUCAS, M. R., 1981: "Santuarios y dioses en la Baja Época Ibérica", en La Baja Época de la Cultura Ibérica, 233- 293. Madrid.

MACKINTOSH, M. 1995: The Divine Rider in the Art of the Western Roman Empire. BAR, Int. Sers., 607. Oxford.

MARCO SIMÓN, F., 1976: "Nuevas estelas ibéricas de Alcañiz (Teruel)", Pyrenae, 12, 73-90. Barcelona.

- 1990: Los celtas. Madrid.

- 1994: "La religión indígena en la Hispania indoeuropea", en Historia de las Religiones de la Europa Antigua, 313-400. Madrid.

MARTÍN VALLS, R., 1992: “Los 'simpula’ celtibéricos", Boletín del Seminario de Estudios de Arte y Arqueología, LVI, 144-169. Valladolid.

MEID, W., 1993-1995: "La inscripción celtibérica de Peñalba de Villastar", Kalathos, 13-14, 347-353. Teruel.

- 1999: "The interpretation of celtiberian inscriptions", en F. Villar y F. Beltrán (eds.) Pueblos, Lenguas y Escrituras en la Hispania Prerromana, 491-497. Salamanca.

MOLINERO, A., 1971: Aportaciones de las excavaciones y hallazgos casuales (1941-1959) al Museo Arqueológico de Segovia. EAE, 72. Madrid.

MOREL, J.-P., 1981: Cerámique Campanienne: les Formes. École Française de Rome. Rome.

OLMOS, R., TORTOSA, T. e IGUÁCEL, P., 1992: "Aproximaciones a unas imágenes desconocidas" en R. Olmos (com.) La Sociedad Ibérica a través de la Imagen. Catálogo de la Exposición, 33-56. Barcelona.

ORTEGA PUENTE, L. y GONZÁLEZ ZAMORA, C., 1975: "La Segovia celtíbera", Boletín Informativo de la Asociación Española de Amigos de la Arqueología, 4, 22-25. Madrid. 
PRINCIPAL-PONCE, J., 2008: “El grupo de NiciasIon: Análisis comercial de una producción de vajilla fina de barniz negro del siglo III a.n.e.”, en J. Pérez y G. Pascual (eds.) Comercio, Redistribución y Fondeaderos. La Navegación a Vela en el Mediterráneo. Actas de las V Jornadas Internacionales de Arqueología Subacuática, 185 198. Valencia.

QUESADA, F. y ZAMORA, M. (eds.), 2003: El caballo en la antigua Iberia. Estudio sobre los équidos en la Edad del Hierro. Real Academia de la Historia. Bibliotheca Archaeologica Hispana, 19. Madrid.

RIGOIR, J. et Y. y MEFFRE, J.-F., 1973: “Les dérivés des sigillées paléochrétienne du Groupe Atlantique", Gallia, 31 (1), 207-263. París.

ROMERO CARNICERO, F., 1976: Las cerámicas polícromas de Numancia. Soria.

- 1988: “Una reflexión sobre la estética celtibérica a partir de las cerámicas de Numancia", en F. Burillo, J. A. Pérez y M. L. de Sus (eds.) Celtíberos. Catálogo de la Exposición (Zaragoza, 1988), 197-199. Zaragoza.

RUANO RUIZ, E., 1976: "Hallazgos de materiales arqueológicos en una escombrera de Segovia", Boletín de la Asociación Española de Amigos de la Arqueología, 5, 15-18. Madrid.

SALINAS, M., 1984-85: "La religión de los celtíberos", Studia Historica, II-III ( $\left.\mathrm{n}^{\mathrm{o}} 1\right), 81-102$. Salamanca.
SÁNCHEZ MORENO, E., 1995-96: “El caballo entre los pueblos prerromanos de la Meseta occidental", Studia Histórica. Historia Antigua, 13-14, 207-229. Salamanca.

SANZ MÍNGUEZ, C., 1997: Los Vacceos: cultura y ritos funerarios de un pueblo prerromano del valle medio del Duero. La necrópolis de Las Ruedas, Padilla de Duero (Valladolid). Arqueología en Castilla y León, Memorias 6. Salamanca.

- 2002: "Panoplias prerromanas en el centro y occidente de la Submeseta norte peninsular", en P. Moret y F. Quesada (eds.) La Guerra en el Mundo Ibérico y Celtibérico (ss. VI - II a. de C.). Collection de la Casa de Velázquez, vol. 78, 87133. Madrid.

SOPEÑA, G., 2005: "La ética agonística y el ritual funerario", en A. Jimeno (com.) Celtíberos. Tras la Estela de Numancia. Catálogo de la Exposición (Soria 2005), 235-238. Soria.

WATTENBERG SANPERE, F., 1963: Las cerámicas indígenas de Numancia. BPH, IV. Madrid.

ZAMORA CANELLADA, A., 1975: “Cerámica celtibérica en la capital segoviana", Estudios Segovianos, XXVII (n 79), 33-41. Segovia.

- 1976: Segovia celtibérica. Cerámicas. Segovia. - 2006: Museo de Segovia. Guía. Segovia. 
